American J. of Engineering and Applied Sciences 4 (3): 314-320, 2011

ISSN 1941-7020

(C) 2014 M.I.S. Ismail et al., This open access article is distributed under a Creative Commons Attribution

(CC-BY) 3.0 license

\title{
Experimental Investigation on Micro-Welding of Thin Stainless Steel Sheet by Fiber Laser
}

\author{
Mohd Idris Shah Ismail, Yasuhiro Okamoto, Akira Okada and Yoshiyuki Uno \\ Division of Industrial Innovation Science, \\ Graduate School of Natural Science and Technology, \\ Okayama University, 3-1-1 Tsushimanaka, Kita-ku, Okayama 700-8530, Japan
}

\begin{abstract}
Problem statement: The miniaturization of components plays an important role for manufacturing in electrical and electronic industries. The joining technology of thin metal sheets has been strongly required. Laser welding with micro-beam and high-speed scanning is a promising solution in micro-welding, because it has high-potential advantages in welding heat sensitive components with precise control of heat input and minimal thermal distortion. Approach: In this study, the characteristics of laser micro-welding of thin stainless steel sheets by using a single-mode CW fiber laser with high-speed scanning system were experimentally investigated. Results: It was clarified that the welding bead width and depth increased with increasing the scanning velocity under a constant energy density condition and high efficient welding was expected by using high-speed laser scanning with Galvano scanner. The utilization of shielding gas was very effective to obtain smooth fusion bead and the combination of micro beam spot and high-speed laser scanning made it possible to obtain good overlap welding of ultra-thin stainless steel sheets. Conclusion: A faster and high quality welding could be achieved by using a single-mode fiber laser with micro-beam and high-speed scanning.
\end{abstract}

Key words: Micro-beam, high-speed scanning, single-mode fiber laser, Galvano scanner

\section{INTRODUCTION}

Recently, many parts and components of electronic devices are being made smaller to meet the requirements of lighter, thinner and compacter in the electrical and electronic industries. Therefore, there exists a demand for high quality and faster joining method of thin metal sheets. Thin metal sheets show very sensitive response to heat input in weld bead and the weld bead geometry is important for joining strength. It is very difficult to weld thin metal sheet using conventional methods, because the excessive heat input leads to blow holes in the bead. The small thickness of thin metal sheets also accompanies the risk of distortion problem in micro-welding. Thus, the minimum heat input to thin metal sheet is effective in both technical and economical points. Technically, less heat input leads to smaller Heat-Affected-Zone (HAZ), less distortion and little loss of materials due to evaporation. Economically, less heat input requires lower laser power that relates to less equipment investment and low running cost.

Laser micro-welding has been considered as an industrial effective tool for these problems, because it has high-potential advantage in welding of heat sensitive components with precision control of heat input, minimal thermal distortion, small HAZ, good mechanical properties and excellent repeatability (Luangpaiboon, 2011; Tsukamoto, 2003). Furthermore, laser welding is well known for its deep penetration capability, although it can be successfully used in conduction mode for thin sheet metal welding (Chen et al., 2009). As a consequence of these advantages, laser welding offers higher welding speed compared to conventional arc welding.

Laser power, scanning velocity, spot diameter and shielding gas are the key parameters to achieve the desired weld bead geometry and appearance. Weld bead geometry is the main requirement of laser welding, while the joining strength is often critical measures of quality. While effects associated with weld bead geometry are already understood well in laser welding in the macro range, the detailed characteristics of laser micro-welding with high-speed scanning have not been sufficiently clarified. Therefore, this study discusses the welding characteristics of thin stainless steel sheet in a laser micro-welding using a single-mode $\mathrm{CW}$ fiber laser

Corresponding Author: Mohd Idris Shah Ismail, Division of Industrial Innovation Science,

Graduate School of Natural Science and Technology, Okayama University,

3-1-1 Tsushimanaka, Kita-ku, Okayama 700-8530, Japan 
with high-speed scanning system on both conditions of the bead-on-plate welding and overlap welding. In order to obtain optimum welding condition, the influence of process parameters on the weld bead geometry was experimentally investigated.

\section{MATERIALS AND METHODS}

A schematic diagram of experimental setup is shown in Fig. 1. In this study, the wavelength of 1090 nm single mode $\mathrm{CW} \mathrm{Yb}$ fiber laser (SPI: SP-100C) was used. The laser was delivered by optical fiber and focused by a telecentric type $\mathrm{f} \theta$ lens of $100 \mathrm{~mm}$ in focal length. Instead of the conventional moving stage, a Galvano scanner was used in order to achieve the high-speed laser scanning. The expander was installed between the isolator and the bending mirror to change the diameter of laser spot. In addition, the welding experiments were carried out in air and in nitrogen gas of a constant pressure $100 \mathrm{kPa}$ to study the influence of shielding gas.

The austenitic stainless steel SUS304 was used as a specimen. The chemical composition of the specimen material is shown in Table 1. The sizes of each specimen were $30 \mathrm{~mm}$ length, $15 \mathrm{~mm}$ width with thickness of 50 and $20 \mu \mathrm{m}$ for bead-on-plate welding and overlap welding, respectively. The fixture plate with an opening slot of $2 \mathrm{~mm}$ was set to avoid the gap distance between specimen sheets in overlap welding. The groove was prepared under the specimen to keep the non-contact space between the specimen and the fixture plate. In addition, the alumina-ceramic plates were located between specimen and fixture plate to minimize the heat loss during welding experiments. The main processing parameters used in the study are given in Table 2.

After the laser welding, the welded specimens were cut perpendicular to the scanning direction for the observation of weld bead by optical microscope. All the specimens were ground and polished. Etching was performed using a solution containing $4 \mathrm{ml} \mathrm{HNO}_{3}, 16$ $\mathrm{ml} \mathrm{HCl}$ and $12 \mathrm{ml} \mathrm{C}_{6} \mathrm{H}_{3} \mathrm{~N}_{3} \mathrm{O}_{7}(5 \%)$ and $10 \mathrm{ml}$ distilled water at room temperature for $3 \mathrm{sec}$. The tensile-shear test was carried out to measure the tensile-shear strength of the overlap weld specimens. A Shimadzu EZ-L test machine was utilized in this study. The crosshead speed was set to $5 \mathrm{~mm} \mathrm{~min}^{-1}$ during the test. The specimen was gripped by the clamp of the testing machine and a tensile-shear force was slowly increased at suitable increments by the mechanical lever system until the fracture of specimen.

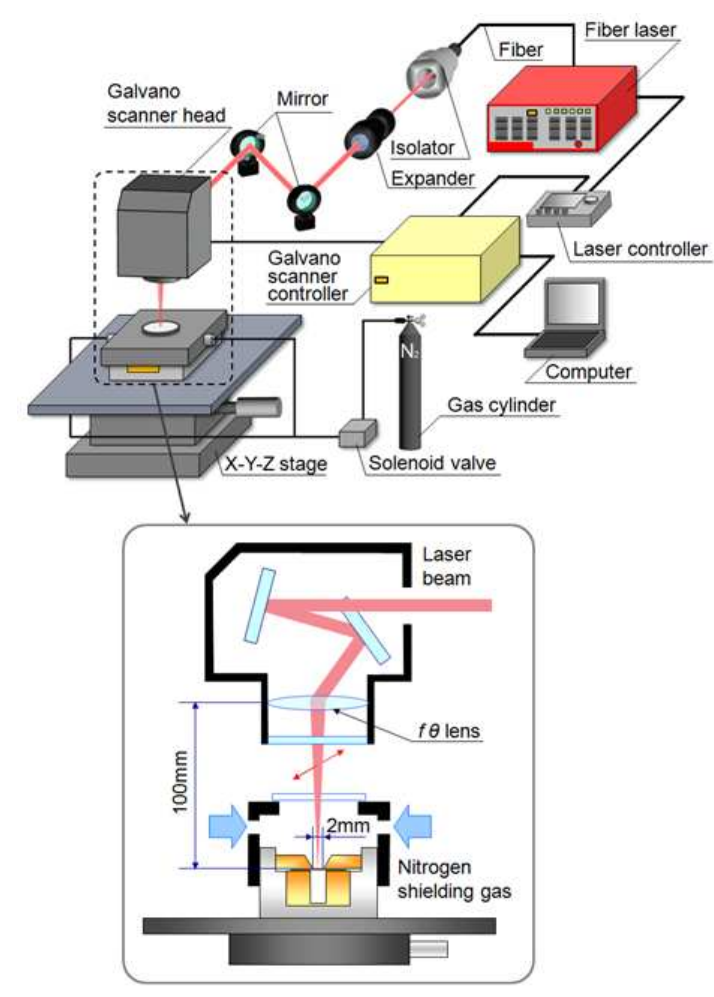

Fig. 1: Schematic diagram of experimental setup

Table 1: Chemical composition of SUS304 Chemical composition (wt. \%)

\begin{tabular}{lllllll}
\hline $\mathrm{C}$ & $\mathrm{Si}$ & $\mathrm{Mn}$ & $\mathrm{P}$ & $\mathrm{S}$ & $\mathrm{Ni}$ & $\mathrm{Cr}$ \\
\hline$<0.08$ & $<1.0$ & $<2.0$ & $<0.045$ & $<0.03$ & $8.0-10.5$ & $18-20$ \\
\hline
\end{tabular}

Table 2: Laser processing parameters

\begin{tabular}{ll}
\hline Parameter & Value \\
\hline Laser power $\mathrm{P}(\mathrm{W})$ & $10,20,30,40,50,60,70$ \\
Scanning velocity V $\left(\mathrm{m} \mathrm{sec}^{-1}\right)$ & $0.5,1.0,1.5,2.0,2.5,3.0$ \\
Spot diameter D $(\mu \mathrm{m})$ & 17.4 (Theoretical), 34.8 \\
\hline
\end{tabular}

\section{RESULTS AND DISCUSSION}

Bead-on-plate welding: The bead-on-plate welding of $50 \mu \mathrm{m}$ thickness thin sheets was carried out with laser power from 10-70 $\mathrm{W}$ and beam diameter of 34.8 $\mu \mathrm{m}$. Figure 2 shows the top surface of welded zone in the atmosphere of air and nitrogen shielding gas. It can be seen that the effects due to the oxidation increase with increasing the peak power in air atmosphere. On the other hand, the nitrogen shielding gas atmosphere is effective to prevent oxidation and creation of slag in the vicinity of the welded zone (Duley, 1999). In this case, surface oxidation has little influence on the size of weld bead. Based on the effect 
of shielding gas, the subsequent welding experiments were conducted in nitrogen shielding gas atmosphere to prevent the oxidation or the weld deterioration.

The relationships between the weld bead geometry and laser power are shown in Fig. 3. At a constant scanning velocity, increasing laser power significantly affects the weld penetration. Increasing the laser power also increases the amount of molten metal causing the weld bead to become wider. It is expected that higher laser power leads to greater weld bead geometry with increasing the power density (i.e., power per unit area). On the other hand, an increase of scanning velocity has a negative influence in this aspect. Working with low scanning velocity, a wider and deeper weld bead can be obtained because of a longer interaction time of laser energy to the specimen.

Since the laser spot diameter is an important factor in determining thermal processing characteristics, the power density can be raised with a smaller spot diameter. Figure 4 illustrates the weld bead geometry with small beam spot diameter of $17.4 \mu \mathrm{m}$. As can be compared with the weld bead geometry of $34.8 \mu \mathrm{m}$ spot diameter (Fig. 3), a smaller spot diameter generates higher power density and resulting in deeper weld bead, which mean the heat is localized in small metal portion. However, the wider spot diameter results in spreading the laser power onto wide area. Therefore, the wider melted area of base metal leads to an increase in weld bead width. It also shows that laser power contributes the secondary effect in the weld bead width with smaller spot diameter of $17.4 \mu \mathrm{m}$. Simultaneously, an increase in laser power results in slightly increase in the weld bead width after the full-penetration was achieved. The effect of laser spot diameter on the weld bead depth from the cross-section view is shown in Fig. 5. It is apparent that a smaller spot diameter can yield a deeper weld penetration under the same laser power. Furthermore, it can be noted that the penetration welding can be attained by low peak power with smaller beam spot diameter.

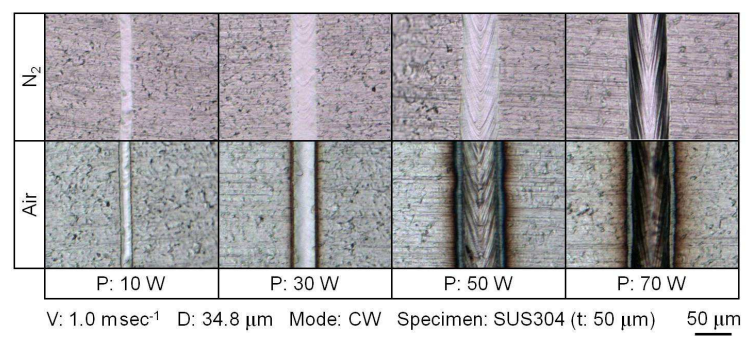

Fig. 2: Top weld bead in air and nitrogen shielding gas

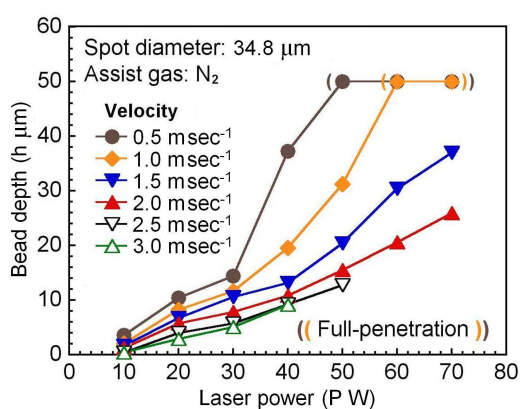

(a)

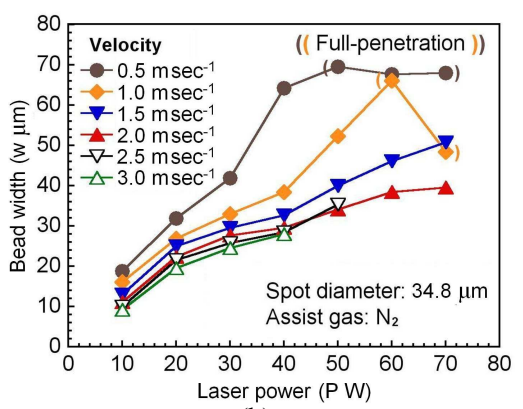

(b)

Fig. 3: Effect of laser power and scanning velocity on weld bead with spot diameter $34.8 \mu \mathrm{m}$ : (a) Bead depth, (b): Bead width

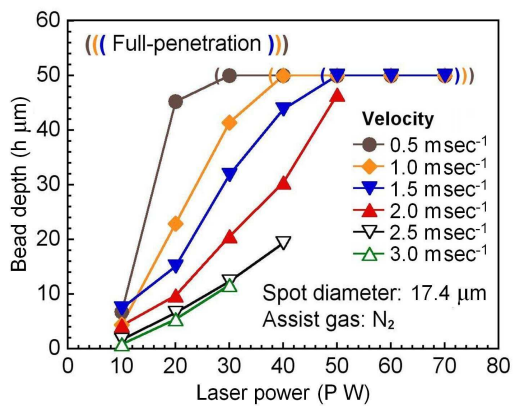

(a)

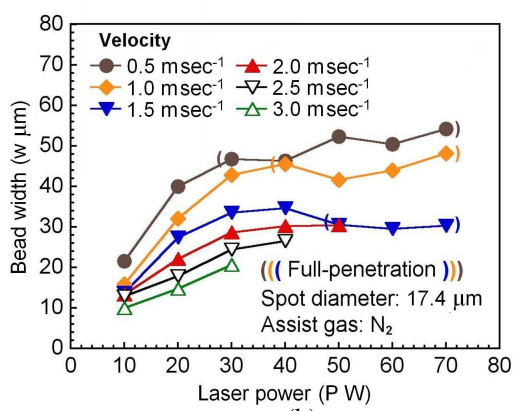

(b)

Fig. 4: Effect of laser power and scanning velocity on weld bead with spot diameter $17.4 \mu \mathrm{m}$ : (a) Bead depth, (b): Bead width 


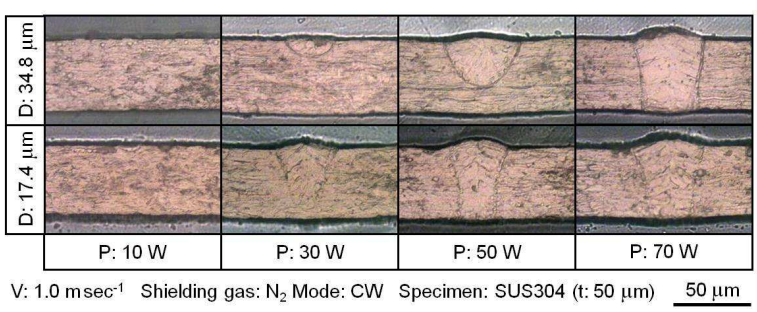

Fig. 5: Effect of spot diameter on weld bead in bead-onplate welding

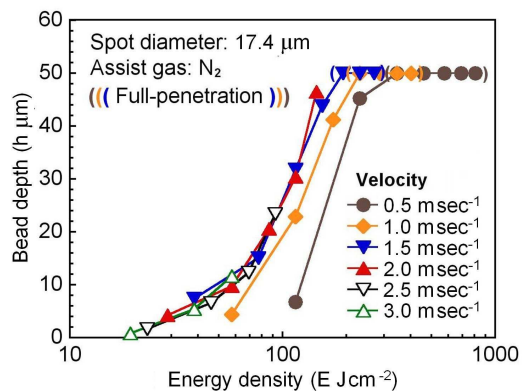

(a)

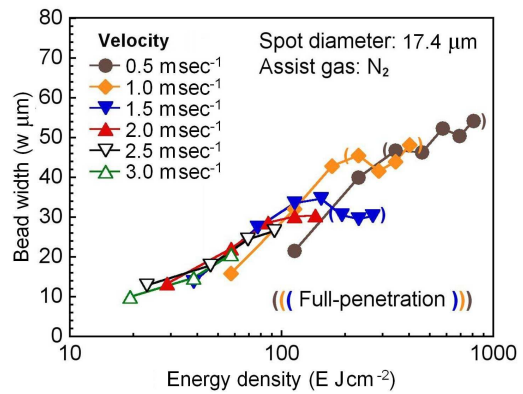

(b)

Fig. 6: Effect of energy density on weld bead with spot diameter 17.4 $\mu \mathrm{m}$ : (a) Bead depth, (b): Bead width

The welding occurs in conduction mode welding, when the laser power is low or spot diameter is large and a shallow and smooth weld pool is obtained. On the other hand, the laser power becomes higher or the smaller spot diameter, a deeper weld bead is generated that is characterized as penetration mode welding (Poprawe, 2009). As can be seen in Fig. 3, it can be found that the keyhole mode welding with fullpenetration starts when the laser power becomes above $40 \mathrm{~W}$ and $50 \mathrm{~W}$ with the scanning velocity of 0.5 and $1.0 \mathrm{~m} \mathrm{sec}^{-1}$ for the $34.8 \mu \mathrm{m}$ spot diameter, respectively.

On the other hand, in the case of $17.4 \mu \mathrm{m}$ spot diameter shown in Fig. 4, the keyhole mode welding with full-penetration starts when the laser powers increase above 20,30 and $40 \mathrm{~W}$ with the scanning velocity of 0.5 ,
1.0 and $1.5 \mathrm{~m} \mathrm{sec}^{-1}$, respectively. In these cases, more than $10^{6} \mathrm{~W} \mathrm{~cm}^{-2}$ of power density is generally required in order to obtain the keyhole formation (Ion, 2005). Since the presence of keyhole generation is different even under the same laser power condition, it is necessary to consider the energy density in this study.

When the weld bead depth and width are plotted against the energy density as shown in Fig. 6 and 7, the relative importance of scanning velocity is reversed and the short interaction times result in the wider and deeper weld bead under the same energy density. Energy density is defined as the laser power divided by the scanning velocity and beam spot diameter at the sheet surface (Ion, 2005). The figures provide clear illustration of the effect of laser energy density and scanning velocity on laser weld bead geometry. It is important to note that the short interaction times result in greater penetration than the long interaction times under the same energy density condition. In other words, if equivalent laser energy is transferred to the specimen by different scanning velocity, the deeper penetration would be accomplished under the higher scanning velocity condition. This is due to the deep penetration induced by the keyhole phenomenon, in which a hole is opened up, so that the laser energy can be penetrated and absorbed deeply into the specimen. In other words, the change in welding mode from conduction to keyhole provides 4-5 times increase in laser power coupling efficiency (Torkamany et al., 2006).

Even the higher welding productivity increases with scanning velocity, some weld defects occur when scanning velocity is beyond a certain limit. It is referred as the critical scanning velocity, which limits the wider application of high-speed welding and prevents further increases in welding productivity. As can be referred from Fig. 3 and 4, the weld defects were obtained in the case of scanning velocity more than $1.5 \mathrm{~m} \mathrm{sec}^{-1}$ and 2.0 $\mathrm{m} \cdot \mathrm{sec}^{-1}$ for $17.4 \mu \mathrm{m}$ and $34.8 \mu \mathrm{m}$ spot diameters, respectively. It can be seen that the range of conditions with welding defects becomes wider for an increase of the scanning velocity. As the scanning velocity is below the limit of critical scanning velocity, the good and smooth weld beads were generated as shown in Fig. 8 and 9. Conversely, the weld defects such as humping, undercut and underfill were observed in high-speed welding when the scanning velocity exceeded the critical scanning velocity. These defects occur in the case of keyhole mode welding, in which the weld pool instability and irregular weld bead formation occurs (Kannatey-Asibu, 2009). 


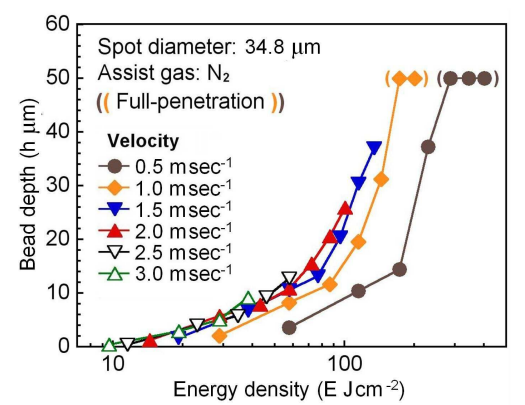

(a)

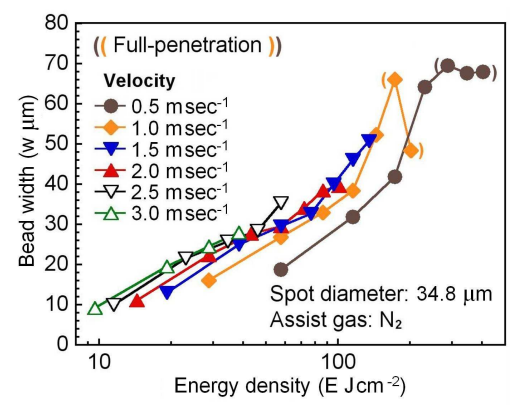

(b)

Fig. 7: Effect of energy density on weld bead with spot diameter 34.8 $\mu \mathrm{m}$ : (a) Bead depth, (b): Bead width

Moreover, the presence of these defects leads to the deterioration of mechanical performance of weld bead. Therefore, it can be considered that the effective welding with good surface of welding bead can be obtained under the machining condition of 1.5 or $2.0 \mathrm{~m}$ $\mathrm{sec}^{-1}$ scanning velocity together with spot diameter of 17.4 or $34.8 \mu \mathrm{m}$, respectively. Furthermore, according to the increasing trend for the energy density of weld bead geometry (Fig. 6 and 7), it can be presumed that the keyhole mode welding in bead-on-plate welding occurs when the energy density is more than $86 \mathrm{~J} \mathrm{~cm}^{-2}$.

Overlap welding: The overlap welding was carried out under the same conditions as the bead-on-plate welding for the specimen thickness of $20 \mu \mathrm{m}$. In the overlap welding, the weld bead is required to penetrate the upper sheet and then reach the lower sheet. Therefore, a keyhole welding mode with a higher power density is needed. The top surface and cross-section of weld bead is shown in Fig. 10. As can be seen from the figure, the melt-down was generated and imperfect welding with $34.8 \mu \mathrm{m}$ spot diameter. The decrease in spot diameter to $17.4 \mu \mathrm{m}$ can enhance the welding quality with a good bead fusion. It can be justified that the variation of penetration profile due to the laser spot diameter is caused by the absorption mechanism of the laser energy. In other words, if there is a small spot diameter, the laser energy is concentrated to the centre of the welding position and a deep penetration is formed. Since the overlap welding was successfully performed by smaller spot diameter, the characteristics of overlap welding were mainly discussed for the $17.4 \mu \mathrm{m}$ spot diameter in the following.

Weld width in the overlap welding is defined as the width dimension of weld bead between the upper and lower sheets as shown in Fig. 11a. As shown in Fig. $11 \mathrm{~b}$, it can be seen that the weld width of overlap welding significantly increases with an increase of laser power and a decrease of scanning velocity. The increase in weld width is caused by the increasing energy density with the high laser power and the longer heating time of low scanning velocity.

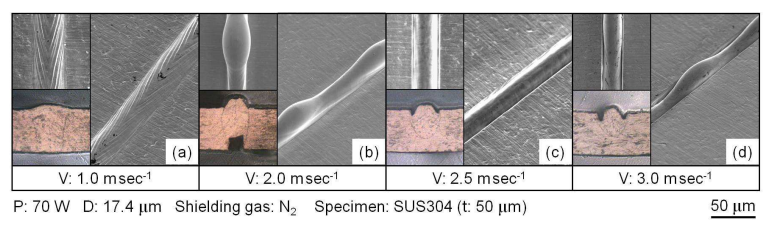

Fig. 8: (a) Good weld bead and (b-d): weld defects with spot diameter $17.4 \mu \mathrm{m}$

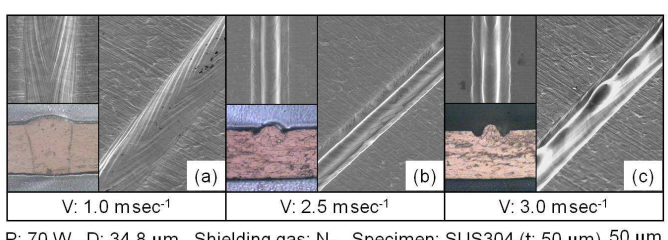

Fig. 9: (a) Good weld bead and (b-c): weld defects with spot diameter $34.8 \mu \mathrm{m}$

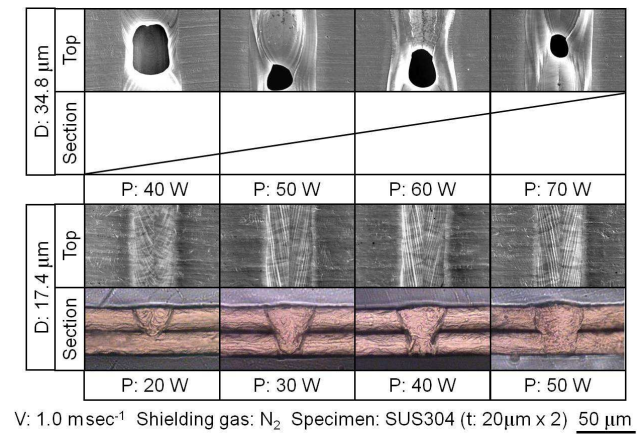

Fig. 10: Effects of spot diameter on weld bead in overlap welding 
Am. J. Engg. \& Applied Sci., 4 (3): 314-320, 2011

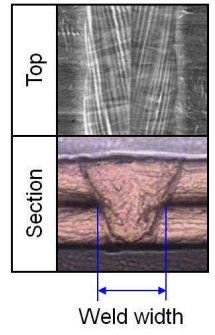

(a)

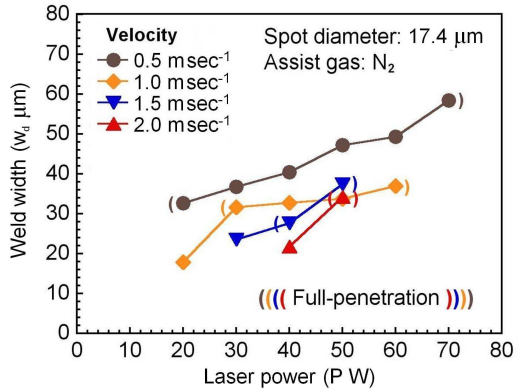

(b)

Fig. 11: Effects of laser power and scanning velocity on weld bead in overlap welding: (a): Measurement of weld width, (b): Weld width

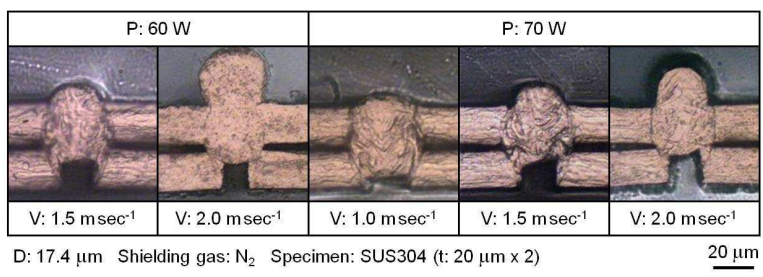

Fig. 12: Weld defects in overlap welding

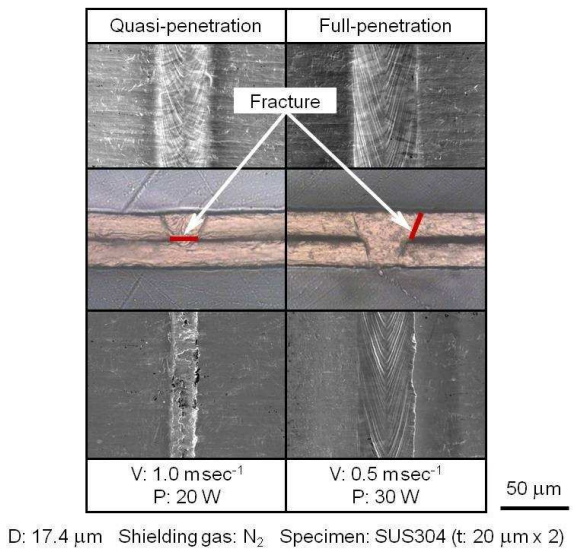

Fig. 13: Fracture on weld bead in overlap welding
In addition, when the laser power was too high at higher scanning velocity, the defects of the weld bead were observed as shown in Fig. 12. These weld defects are suspected to be produced by greater keyhole instabilities with increasing scanning velocity. The underfill defect started from the scanning velocity of $1.0 \mathrm{~m} \mathrm{sec}$ with the highest laser power. Subsequently, the underfill with humping defects were found, when the scanning velocity is more than 2.0 $\mathrm{m} / \mathrm{s}$. Moreover, the overlap welding was ineffective with either scanning velocity more than $2.5 \mathrm{~m} \mathrm{sec}^{-1}$ or laser power less than $10 \mathrm{~W}$.

Evaluation of joining strength of welded part: Tensile-shear tests are commonly used to evaluate the strength of laser weld. Fig. 13 shows the fracture on weld bead at overlap welding. It was found that, in the quasi-penetration condition, the fracture occurs on the weld bead which is located at the bottom surface of the upper sheet and the top surface of the lower sheets. In other words, it is parallel to the specimen surface. However, in the full-penetration condition, the fracture occurs at the weld bead boundary of upper specimen which is perpendicular to the test load. From these viewpoints, the calculations of tensile-shear stresses for quasi- and full-penetration conditions are different. The calculation equations of tensile stress and shear stress for each condition are shown in Fig. 14.

The tensile stress and shear stress of overlap welding are shown in Fig. 15 for various laser powers and scanning velocities. The tensile-shear test results show that the welds of the lowest scanning velocity with 60 and $30 \mathrm{~W}$ take the maximum values for tensile and shear stresses, respectively. At higher scanning velocities of 1.5 and $2.0 \mathrm{~m} \mathrm{sec}^{-1}$, it demonstrates that the weld strength of the overlap welding increased with increasing the laser power, while it decreased with increasing the scanning velocity, due to the increase in the fusion zone. It also can be seen that the lower weld strength was obtained at the quasi-penetration, compared with the full-penetration which lead to the higher weld strength. However, the results show that the weld strengths of lower scanning velocities of 0.5 and $1.0 \mathrm{~m} \mathrm{sec}^{-1}$ with higher laser power lead to inferior values. The sudden drop in weld strength is probably due to the overheating, which is affected from the heat conduction generated by the front spot of laser beam, as the curvature weld bead profile can be observed. This condition causes the loss of materials due to vaporization, melt expulsion and structural degradation. 

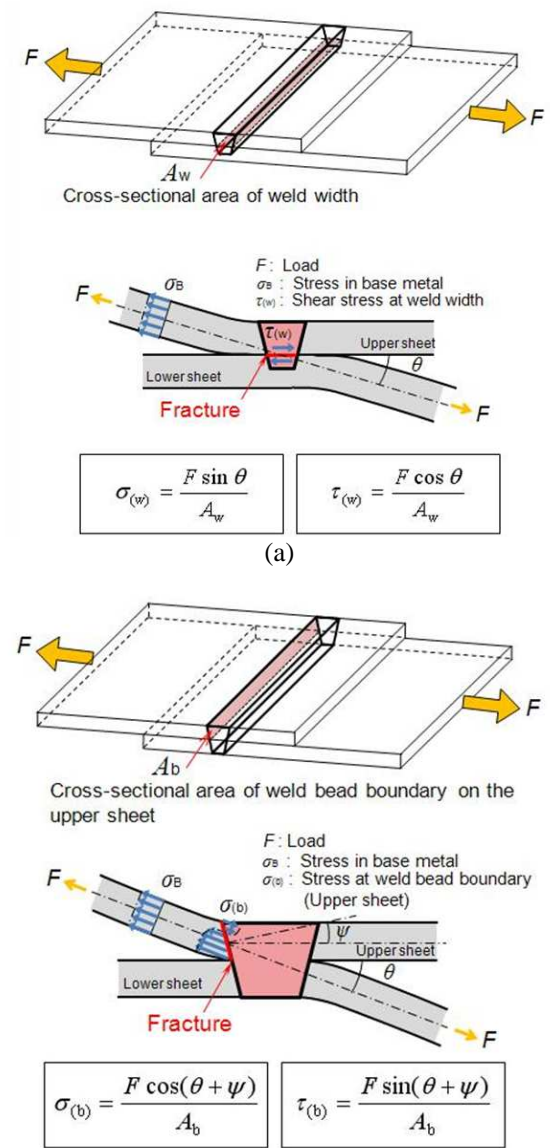

(b)

Fig. 14: Calculation of tensile and shear stresses: (a): Quasi-penetration, (b): Full-penetration

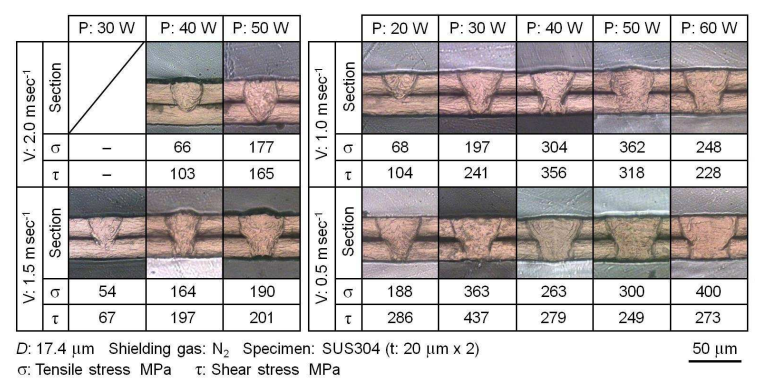

Fig. 15: Tensile and shear stresses in overlap welding

It also can be considered this feature occurs, when the width dimension of weld bead at the bottom surface is larger than the sheet thickness. As can be seen in Fig. 15, the deeper weld bead depth gives a wider weld width and consequently, larger tensile and shear strengths, which indicates that the joint strength increased with increasing the weld bead depth until the full-penetration. Then, the highest strength is obtained. It can be concluded that size and profile of weld bead significantly affect the weld strength in the overlap welding.

\section{CONCLUSION}

The micro-welding using single-mode fiber laser with high-speed scanning has a possibility for obtaining high quality and fast joining of ultra-thin stainless steel sheet. Main conclusions obtained in this study are as follows:

- The energy density has an obvious effect on the weld bead geometry. The weld bead becomes larger with increasing energy density. Under the same energy density condition, higher scanning velocity could yield excellent weld bead geometry

- The combination of small spot diameter and nitrogen shielding gas could prove to be the effective welding condition

- Welding defects appear in weld bead, when the laser power and scanning velocity exceed the optimum laser welding condition

- The higher weld strength could be achieved in the overlap welding of ultra-thin sheet with a smaller spot diameter and higher scanning velocity

\section{REFERENCES}

Chen, W., P. Ackerson and P. Molian, 2009. $\mathrm{CO}_{2}$ laser welding of galvanized steel sheets using vent holes. Mater. Design, 30: 245-251. DOI: 10.1016/J.MATDES.2008.05.009

Duley, W.W., 1999. Laser Welding. 1st Edn., WileyNew York, ISBN: 0471246794, pp: 251.

Ion, J.C., 2005. Laser Processing of Engineering Materials: Principles, Procedure and Industrial Application. 1st Edn., Butterworth-Heinemann, Boston, ISBN: 0750660791, pp: 556.

Kannatey-Asibu, E., 2009. Principles of Laser Materials Processing. 1st Edn., John Wiley and Sons, Hoboken, N.J., ISBN-10: 0470177985, pp: 819.

Luangpaiboon, P., 2011. Constrained response surface optimization for a laser beam welding process. J Math Stat, 7: 5-11. DOI: 10.3844/jmssp.2011.5.11

Poprawe, R., 2009. Tailored Light 2: Laser Application Technology. 1st Edn., Springer, Berlin London, ISBN-10: 3642012361, pp: 644.

Torkamany, M.J., M.J. Hamedi, F. Malek and J. Sabbaghzadeh, 2006. The effect of process parameters on keyhole welding with a $400 \mathrm{~W}$ Nd:YAG pulsed laser. J. Phys. D: Appl. Phys., 39: 4563-4563. DOI: 10.1088/0022-3727/39/21/009

Tsukamoto, S., 2003. Laser welding. Welding Int., 17: 767-774. DOI: 10.1533/wint.2003.3172 